\section{ekf}

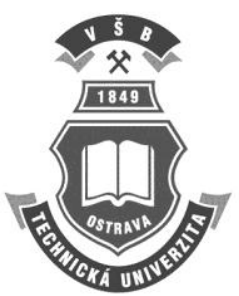

\title{
Assessment of the variability of technical coefficients from input-output tables in the Czech Republic during 1995-2010
}

\author{
Milan KAŠTAN, VŠB-TU Ostrava ${ }^{i}$
}

\begin{abstract}
The variability in technical coefficients calculated based on the input-output tables published by the Czech Statistical Office for the period 1995 to 2010 is examined in the present paper. The low variability of coefficients is a prerequisite for their applicability in macroeconomic forecasts and analysis. The paper progressively deals with the meaning of technical coefficients, the method of their calculation, and the characteristics of variability. It was found that the variability of coefficients is high and, therefore, that the technical coefficients, with few exceptions, are unsuitable for making predictions.
\end{abstract}

\section{Keywords}

Input-output tables, structural analysis, supply and use tables, System of National Accounts, technical coefficients

JEL Classification: L60, L70, L80, L90, L16

\footnotetext{
${ }^{\text {i }}$ Department of National Economy, Faculty of Economics, VŠB-Technical University of Ostrava, Sokolská 33, 70121 Ostrava, Czech Republic.

milan.kastan@vsb.cz

This paper has been funded by a grant from Students Grant Project EkF, VŠB-TU Ostrava within the project SP2012/105.
}

\section{Introduction}

The System of National Accounts (SNA) is a comprehensive statistical and macroeconomic model that enables us to describe and track various patterns of economic activity within a particular economy. For an introduction to the SNA, please see some of the many handbooks (United Nations, 1993, 2009; Eurostat, 1996) and textbooks (LeQuiller and Blades, 2006; Hronová and Hindls, 2000) on the topic.

Input-output (I-O) tables are an important outcome of the SNA, which are used for so-called technicaleconomic linkages analyses (Hronová and Hindls, 2000). It is broadly accepted (keeping in mind the several assumptions for I-O construction developed in the SNA manual) that I-O tables serve to describe and help understand relations among industries, institutional sectors, and non-residents (see Hronová et al., 2009). By contrast, the forecast ability of I-O tables and other SNA outcomes are perceived ambiguously. For a comprehensive list of various I-O applications, see Eurostat (2008). For instance, I-O tables can describe how the final consumption of households is distributed among car-producing, food-producing, and services-producing industries and other residential and non-residential statistical units. The effect of household final consumption changes and their impacts on particular industries can be estimated roughly.

Technical coefficients (TCs) can be derived from I-O tables, and they describe the intermediate relations among industries. Although TCs were originally designed to capture technology, they cannot be interpreted without knowledge of some of their shortcomings (ten Raa, 2007). Simply put, TCs describe the relations of industries that deliver inputs (commodities, services) to industries that use these inputs to produce outputs. An increase in demand for the 
outputs of a particular industry (A) will increase the intermediate consumption of the outputs of those industries $(\mathrm{B}, \mathrm{C}, \ldots)$ that deliver to the industry $(\mathrm{A})$. A growing group of macroeconomic models is known as INFORUM. ${ }^{1}$ These models use inter-industrial linkages for both public policy analysis and business forecasting (Almon, 1991).

Economic policymakers use the knowledge of these coefficients (in terms of INFORUM) to estimate the impact of their policies. For example, the automotive industry in EU countries is heavily connected to other industries (for empirical evidence, see Kaštan, 2009), and this might be one of the reasons why fiscal stimulus in the form of the scrappage program measure was adopted in some EU countries (e.g. Germany, Italy, France) following the 2008 economic downturn. This stimulus aimed to pump up the money in the whole economy through the automotive industry. ${ }^{2}$

When TCs are invariant over long time periods, they are more suitable for the abovementioned kinds of predictions and measures. LIFT ${ }^{3}$ models use fundamental I-O identities (Meade, 2001). A range of other practical applications is based on the assumption of stable inter-industrial relations. Generally speaking, the inverse relation between TC variability and their suitability for prediction, analysis, and policymaking is assumed.

I-O analysis is widely used not only at a national level (e.g. Kulišić et al., 2007), but also at a regional level (see Morrison and Smith, 1974). Despite the fact that the stability of TCs affects the possibilities for drawing conclusions from I-O analysis, the stability of coefficients is not the key issue among economists. As Kurz (2011) points out, the problems of contemporary I-O analysis offer perspectives for its further development. Few articles assess TCs variability; however, let us mention the assessments of Norwegian (Sevaldson, 1970) and French data (de Mesnard, 1997). No assessment of the stability of TCs has been published in Czech journals.

This article assesses TCs variability in the Czech Republic during 1995-2010. The paper progressively deals with the introduction of I-O tables (Section 2). This is followed by an explanation of the meaning of TCs and the method of their computation (Section 3). The variability of individual TCs is assessed in Section 4. This section presents commented results for various indicators of variability. This is followed by conclusions.

\footnotetext{
${ }^{1}$ INterindustry FORecasting at the University of Maryland.

2 The effectiveness of this measure is evaluated ambiguously and is not the subject of this article.

${ }^{3}$ Long-term Inter-industry Forecasting Tool.
}

\section{I-O Tables}

I-O analysis was developed by Wassily Leontief, 1973 Nobel Prize Laureate (Nobel Prize, 2011). His main articles and essays are collected in I-O economics (Leontief, 1966). His work still influences the international standards of national accounting, such as SNA 1993, ESA ${ }^{4}$ 1995, and SNA 2008, which are nowadays implemented by national statistics offices. The main contribution of I-O analysis at a macroeconomic level lies in its ability to track the links between industries that are important for economic policymakers and analysts.

I-O tables consist of two main types of tables, namely Supply and Use Tables (SUT; sometimes called make-use tables) and Symmetric I-O Tables (SIOT). ${ }^{5}$ SUT are constructed annually by national statistics offices. They are directly linked to other data within the SNA and are subject to less statistical distortion than SIOT. By contrast, SIOT are usually published by national statistics offices on a five-year basis. Their analytical value is higher and they go more hand in hand with Leontief's original theoretical background, but their construction is based upon strong assumptions (for some early critiques and empirical evidence, see Gerking, 1976 and Sevaldson, 1970; for the basics of SIOT construction, see Hronová et al., 2009); for more advanced discussion, see Vavrla and Rojíček, 2006). There are two basic types of SIOT and four main sets of assumptions for their construction. New methods of SIOT construction were developed recently (Bohlin and Widell, 2006). It is generally accepted that SIOT ought to be used in situations when data cannot be found in SUT or from other sources.

The structure of I-O tables is too extensive to be described in this article; for detailed information, see Eurostat (2008). Let us focus on the important part of I-O tables, namely the intermediate consumption matrix (ICM). The ICM captures goods and services that are used in the process of production by industries (all values are denoted at current prices). It consists of $I$ rows and $J$ columns. Each element of the ICM expresses how many inputs of the $i$-th industry (or commodity) are used by the $j$-th industry (or commodity) to produce the total amount of product or service of the $j$-th industry (or commodity).

\footnotetext{
${ }^{4}$ ESA 1995 stands for the European System of Accounts, which is an extension of SNA 1993. The number refers to the year of introduction. The ESA handbook is used by EU countries.

5 The system of I-O tables also includes the tables that connect SUT to another SNA output (i.e., Institutional Sector Accounts).
} 
The form of the ICM varies according to the type of I-O table. The ICM in SIOT can be displayed in a commodity $\times$ commodity or a industry $\times$ industry breakdown and is always square. The ICM in SUT is rectangular (need not to be square) and usually displayed in a commodity $\times$ industry breakdown, which mean that rows (commodities) are classified according to the CPA classification and columns are classified according to the NACE classification. The size of the ICM depends on the level of aggregation. The standard size of the ICM in SUT published by the Czech statistical office in current prices is 88 rows and 88 columns. The results presented in this article are obtained by working with these SUT.

The ICM within SUT is extended to include rows that contain information about each industry. This information is derived mainly from production account (K.1 - Consumption of fixed capital; B.1g Gross value added; D.29 - Other taxes for production; D.39 - Other subsidies; P.1 - Total production for each industry (which is also the column sum); marking corresponds to ESA 1995 manual).

Let us denote each element of the ICM as $C_{i j}$. $C_{i j}$ expresses the input denoted in the $i$-th row, which is used to calculate the total production of output denoted in the $j$-th column. The sum of the $j$-th column is denoted as $X_{j}$ and can be computed via equation (1): ${ }^{6}$

$$
\sum_{i=1}^{I} C_{i j}=X_{j} \quad(j=1, \ldots, J) .
$$

Another extension of the ICM within SUT refers to the columns. Additional columns express those outputs not used for intermediate consumption but for other purposes (final use). They are not part of the ICM, but let us mention some of them: expenditures for final consumption of households (P.3 S.14); government final expenditures (P.3 S.13), gross capital formation (P.5), and export (P.6). ${ }^{7}$ The sum of all elements in each row expresses the total value of the $i$-th input used for intermediate consumption. This can be denoted $Y_{i}$ and computed via equation (2):

$$
\sum_{j=1}^{J} C_{i j}=Y_{i} \quad(i=1, \ldots, I) .
$$

\footnotetext{
${ }^{6}$ This sum can be conceived in two ways: 1) as the sum of all commodity inputs to the ICM for the $j$-th industry or 2 ) as the total production (P.1) of the $j$-th industry (which is the sum of all commodity inputs to the ICM for the $j$-th industry plus gross value added (B.1g)). The presented results were computed using the second approach. Some might object that items of gross value added or valuation differences may hide the instability of coefficients; however, the P. 1 value is a balance sheet item and therefore is considered to be more accurate. This approach also conforms to the HawkinsSimons condition, as explained in Section 3.

${ }^{7}$ Marking of elements corresponds to the ESA 1995 manual.
}

Equation (3) is valid for the standard ICM (without extension) in SUT and SIOT:

$$
\sum_{j=1}^{J} X_{j}=\sum_{i=1}^{I} Y_{i} .
$$

It expresses that the total amount of inputs (Y) into intermediate consumption has to be equal to the total amount of outputs (X). ${ }^{8}$

I-O tables are an important outcome of the SNA. Their analytical value lies in their ability to capture relations among industries and in their data consistency with other parts of the system. Data in I-O tables enable us to compute TCs, as discussed later.

\section{TCs}

TCs serve to describe the technical-economic linkages between different sectors and industries (also called inter-industrial linkages). They are usually unit indicators that are related to the unit of output or input. Their meaning can usually be deduced from the way they are computed. Basic ones can be computed straight from the ICM, whereas the more complicated use other quadrants of SUT or SIOT. We can compute not only direct linkages but also backward linkages using SIOT. For more information about the computation of backward linkages and their empirical evidence in the EU, see Kaštan (2009).

This article examines the variability of basic TCs in the Czech Republic over a period of 15 years (1995-2010). Those coefficients are computed from data (SUT at current prices) that are publicly available on the webpages of the Czech statistical office. ${ }^{9}$ The meaning of the examined TCs is explained and their computation is described. Hereafter, TCs means only those that are examined in this article.

TC expresses the value of the $i$-th input that is needed to produce one unit of the $j$-th output. TC is denoted as $a_{i j}$ and can be computed based on the ICM and vector of production $(X)$ as displayed in equation (4):

$$
a_{i j}=c_{i j} / X_{j}
$$

\footnotetext{
${ }^{8}$ In SIOT (whether the ICM follows a commodity $\times$ commodity or a industry $\times$ industry structure), the vector of final consumption is denoted by the letter Y. Notation problems occur if the ICM has a commodity $\times$ industry structure (in SUT). It is thus necessary to distinguish between commodity and industry classification (see Bohlin and Widell, 2006). Nonstandard notation is used in order to simplify equations. The presented results are not affected by this simplification. ${ }^{9}$ The broadest possible database at the time of the article's submission.
} 
The higher the value of TC the more important the relation between the $i$-th input and the $j$-th output is. ${ }^{10}$ TC in period $\mathrm{t}$ is computed as (5) and forms matrix $A_{t}$ :

$$
a_{i j}^{t}=c_{i j}^{t} / X_{j}^{t}
$$

TCs conform to the Hawkins-Simons (1949) condition, which states that the value of all inputs used to produce the $j$-th output should not exceed the value of the $j$-th output produced. ${ }^{11}$ In terms of a unit indicator, this condition is expressed by equation (6):

$$
\sum_{i=1}^{I} a_{i j}<1 \quad(j=1, \ldots, J) .
$$

We can estimate the change in demand for the $i$-th input (demand from the $j$-th industry) if the demand for the $j$-th output changes. As shown in equation (5), TC describes the technical relations in the current period. Its computation does not take into account TCs from previous periods. TCs can change over time and this should be kept in mind during the abovementioned estimations. Therefore, TC variability is the central point of interest in this paper.

\section{Variability}

Described TCs express the ratio between the value of inputs of the $i$-th commodity to the $j$-th industry and the value of the total production of the $j$-th industry (equation 4). In other words, TC captures the specific relation between a specific commodity and industry at a specific time (equation 5). The variability measures presented in this paper describe how this specific relation developed over the observed period. If variability is low, the relation is stable and vice versa.

Absolute variability can be measured via variation range (VR) and standard deviation (SD). SD divided by the arithmetic mean of the observed values is a measure of relative variability and is often called the coefficient of variance $(\mathrm{CV})$. Calculations of relative variability are justified in situations where we want to compare the variability of different groups of values, which is our case. Each specific commodity $\times$ industry relation described by $\mathrm{TC}$ has a specific dimension given by the technology of production - for the illustration of this point, note that the scale of the relation of the input of tobacco to the production of furniture is considerably lower than the relation of the input of oil and natural gas to the manufacture of petroleum.

\footnotetext{
${ }^{10}$ For example, the value $a_{5: 8}=0.5$ means that the input of the fifth commodity value of $0.5 \mathrm{CZK}$ is needed to produce the output of the eighth industry value of $1 \mathrm{CZK}$. This relation is strong, because one particular input represents half of the value of the output. Such a high value for TC is unusual, as can be seen from the results of TC averages.

${ }^{11}$ Further explained in Chiang and Wainwright (2005).
}

VR indicates the difference between the highest and lowest value of the TCs in the reference period, while SD indicates the average distance of the variables from their arithmetic means. VR and SD are both measures of absolute variability; the higher their value the higher is TC variability.

Variability measures for TC were computed for $a_{i j}^{t}$ for $(i, j=1,2, \ldots, 85 ; t=1, \ldots, 15$; where $i$ represents commodities according to the CPA classification; $j$ represents industries according to the NACE classification; $t=1$ represents the 1995 period, and $t=15$ represents the year 2010. The ICM in the used SUT was slightly modified. Data on commodities classified in the 97, 98, and 99 classes of CPA and industries classified in the 97, 98, and 99 classes of NACE were not included in the variability tests ${ }^{12}$ because their values were mostly zeros.

For each period $(t=1, \ldots, 15)$, there is a matrix of $A_{t}$, which has 7225 elements $(85 \times 85)$. Each element of this matrix shows a specific relationship (given by equation 5), which developed over the past 15 years. By observing this variability, we see how TC was stable over time. The value of TC average is the average value of the described relationship, which can suggest the importance of observed relationship. TCs that are denoted $a_{i j}$ (without an upper index $t$ ) represent the value for the entire observed period.

The scatter/dot diagram in Figure 1 displays the values of VR and SD for all observed TCs. The horizontal axis represents VR values and vertical axis represents SD values. Both measures of absolute variability provide similar results. Coefficients whose variability is measured by SD are higher; they also have a higher variability as measured by VR.

Average values for each $a_{i j}$ (for each specific relation between commodity and industry during the observed period) were computed (further identified as the TC average). Table 1 shows the percentiles of the TC average. It is noteworthy that about $95 \%$ of TC average values are less than 0.026 . This means that more than $95 \%$ of the inputs are worth less than $2.64 \%$ of the outputs.

Of the 7225 inter-industrial relations evaluated, it was found that the majority are weak. Most TCs do not represent inter-industrial linkages to a substantial degree.

\footnotetext{
12 These classes of CPA and NACE relate to the services of exterritorial organisations and those for households' own needs.
} 


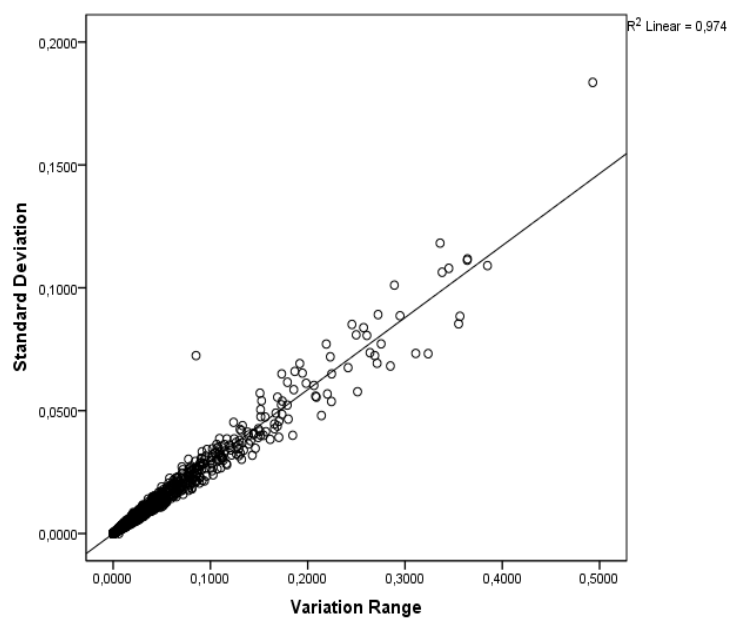

Figure 1 Absolute TC variability in the Czech Republic during 1995-2010.

According to the TC average value, that about half of all TCs are less than 0.01 (see Table 1). The value of TC average (0.01) represents a situation in which a specific $(i$-th) input contributes to the total production of the $j$-th output by $1 \%$ of the value of the total production of the $j$-th output (on average during the observed period). This means that about half of all I-O relations are relations in which is the value of the input of a specific commodity to the production of a specific industry is less than $1 \%$ of the value of the production of the specific industry. In other words, the direct impact of the total production of the $j$-th output that increases by 100 million would increase the $i$-th input value by 1 million (because the $j$-th input is needed for the $j$-th output production).

Table 2 shows the extreme values for TC average. We can see that the I-O link that clearly dominated in the Czech Republic over the observed period is represented by $a_{5 ; 18}$, which has an average value of 0.701 . It can be found (in SUT) that the fifth row and 18th column refers to the input of Oil and natural gas to the Manufacture of coke, refined petroleum products and nuclear fuel industry. Thus, $70 \%$ of the value of the production of refined petroleum products is (on average during the observed period) composed of the value of that particular input - oil and natural gas.
Table 2 Extreme values for TC averages

\begin{tabular}{|r|c|c|}
\hline TC Average & Coefficient & Value \\
\hline Highest 1 & $\mathrm{a}_{5 ; 18}$ & 0.701 \\
\cline { 2 - 3 } 2 & $\mathrm{a}_{25 ; 25}$ & 0.583 \\
\cline { 2 - 3 } 3 & $\mathrm{a}_{14 ; 14}$ & 0.471 \\
\cline { 2 - 3 } 4 & $\mathrm{a}_{1 ; 11}$ & 0.413 \\
\cline { 2 - 3 } 5 & $\mathrm{a}_{65 ; 65}$ & 0.410 \\
\hline Lowest 1 & - & $0.000^{\mathrm{a})}$ \\
\hline
\end{tabular}

a) Only a partial list of cases with a value of 0 is shown in the table of lower extremes. The total number of 0 coefficients is 1053 .

The main objective of this article is not to describe particular inter-industrial linkages, which is why individual coefficients are described only briefly. Further information about the meaning of particular rows and columns can be found in the abovementioned classification or in the original SUT. Figure 2 displays the distribution of TC average values (i.e., it graphically complements the values given in Table 1 and Table 2). The vertical line (its value of TC average is 0.026) divides the graph into two parts. We can see that $95 \%$ of the values lie on the left-hand side of the line, while only 30 values are greater than 0.2 , which represents less than $0.5 \%$ of all values.

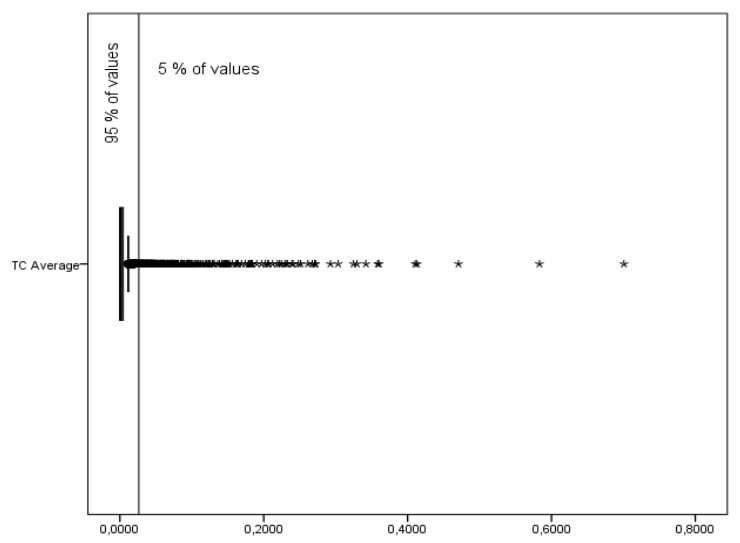

Figure 2 Distribution of TC average

The higher the value of TC the stronger is the direct linkage between inputs and outputs. Stronger linkages between inputs and outputs (measured by TC value) may show, theoretically, higher values of absolute variability compared with weaker links. This is why relative variability is dealt with further in the

Table 1 Percentiles of TC averages in the Czech Republic during 1995-2010

\begin{tabular}{|c|c|c|c|c|c|c|c|}
\hline \multirow{3}{*}{ TC Average } & \multicolumn{7}{|c|}{ Percentiles } \\
\cline { 2 - 9 } & 5 & 10 & 25 & 50 & 75 & 90 & 95 \\
\cline { 2 - 9 } & 0.000000 & 0.000000 & 0.000095 & 0.001053 & 0.004714 & 0.013860 & 0.026340 \\
\hline
\end{tabular}


text. This indicator of variability is more convenient for our purposes, as it takes into account the importance of direct inter-industrial linkages. Values of $\mathrm{CV}$ close to 0 represent low variability and vice versa.

Figure 3 displays a histogram of CV. It can be observed that most TCs have a CV value between 0 and 1 . Some outliers are visible on the right-hand side of histogram. The values assigned to bars in Figure 3 indicate the frequencies of TC with specific relative variability values.

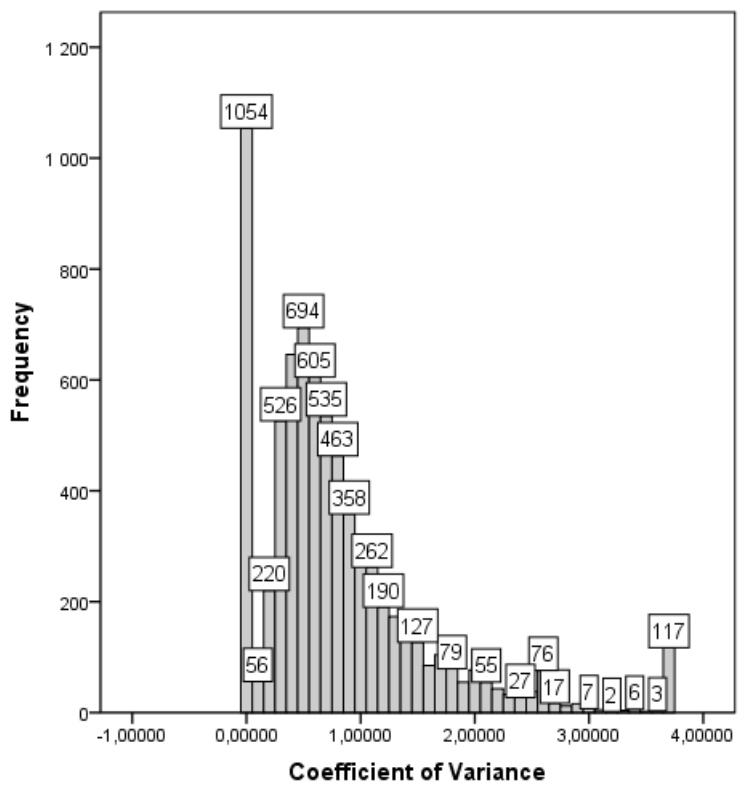

Figure 3 Histogram of $\mathrm{CV}$ values

It can also be said that 117 of the 7225 observed TCs have a CV of 3.7 according to Figure 3. Therefore, it can be argued that these coefficients are not suitable for analytical use. They represent the direct linkages between industries that are unstable during the observed period, as the commodity $\times$ industry relation changes over time. It should be considered whether these TCs describe direct linkages that are rather important (with high TC average values) or insignificant. Finding high TC variability of minor importance is less an adverse result than finding high TC variability of high importance. In other words, finding that the input of agricultural commodities to the production of IT services has a CV equal to 3.7 during the observed period is not a bad result (in terms of TC variability). This is because the direct linkage between agriculture and information technology services does not play an important role in the industrial structure of the observed economy (its TC average equals $1.582 \times 10^{-6}$ ). Inaccuracies arising from a stable relationship are not serious because the interindustrial linkage is weak.
The scatter/dot diagram in Figure 4 shows whether the extreme values of $\mathrm{CV}$ are those TCs that represent strong I-O linkages (high value of TC average) or the rather less important technical-economic linkages (low value of TC average). Relative TC variability ranges from 0 to 3.7. Multiplying the CV value by 100 gives us a percentage share of SD to the mean value; hence, a CV of 3.7 represents extremely high TC variability. We can see that TCs with a rather high TC average have quite low $\mathrm{CV}$, but this is not statistically verified.

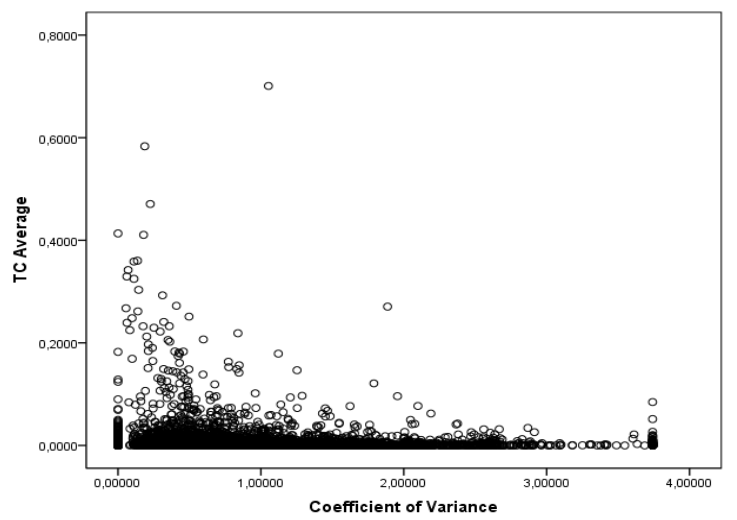

Figure 4 Relative TC variability to their averages in the Czech Republic during 1995-2010

\section{Conclusions}

The inter-industrial linkages resulting from I-O data are described by TCs, which have a wide range of use in macroeconomic theory and praxis. Knowledge of inter-industrial relations helps explain the production processes at the macroeconomic level. Fluctuations in the production of a particular industry are also reflected in other industries. The intensity of this impact can be estimated using TCs, which are also used to capture and quantify production relations. The inter-industrial linkages described by SUT are used in the construction of SIOT.

The simple use of TCs assumes that these interindustrial linkages are linear. This assumption is often criticised, but frequently used. The linearity of interindustrial relations goes hand in hand with the stability of TCs, as described in third section of this paper. This article assessed TC variability in the Czech Republic over the period 1995-2010. The low variability of TCs could be viewed positively by those who compile and work with SIOT, such as economic analysts and policymakers. However, it was found that TCs in the Czech Republic during 1995-2010 show a high rate of relative variability, which means that inter-industrial linkages change over time considerably. Generally speaking, it is neither recommended to use TCs for naïve predictions nor to stick to the assumption of 
linear linkages among industries while constructing SIOT.

The average values of individual TCs are low, which means that only a small share of all coefficients represent strong and important linkages between commodity inputs and industry outputs. Few interindustrial relations can be considered to be strong in terms of the TC average value.

One can suppose that more important interindustrial linkages show lower levels of relative variability when examining the $\mathrm{TC}$ average- $\mathrm{CV}$ relation. This is shown in Figure 4, and it can be used to justify the assumption of linear inter-industrial linkages. Nevertheless, this relation should be subject to further research. Similarly, the TCs of other European countries could be calculated and investigated.

\section{References}

ALMON, C. (1991). The INFORUM approach to interindustry modelling. Economic Systems Research 3(1): $1-8$.

http://dx.doi.org/10.1080/09535310600653164

BOHLIN, L., WIDELL, L.M. (2006). Estimation of commodity-by-commodity input-output matrices. Economic Systems Research 18(2): 205-215. http://dx.doi.org/10.1080/09535310600653164

CHIANG, A.C., WAINWRIGHT, K. (2005). Fundamental Methods of Mathematical Economics. New York: McGraw-Hill.

EUROSTAT (2008). Eurostat Manual of Supply, Use and Input-Output Tables. Luxembourg: Office for Official Publications of the European Communities.

EUROSTAT (1996). ESA 1995, European System of Accounts. Luxembourg: Office for Official Publications of the European Communities.

GERKING, S.D. (1976). Input-output as a simple econometric model. Review of Economics and Statistics 58(3): 274-282.

http://dx.doi.org/10.2307/1924949

HAWKINS D., SIMONS, H.A. (1949). Note: some conditions of macroeconomic stability. Econometrica 17(4) 245-248. http://dx.doi.org/10.2307/1905526

HRONOVÁ, S., FISCHER, J., HINDLS, R., SIXTA, J. (2009). Národni účetnictví: nástroj popisu globální ekonomiky. Praha: C.H. Beck.

HRONOVÁ, S., HINDLS, R. (2000). Národni účetnictví: koncept a analýzy. Praha: C.H. Beck.

KAŠTAN, M. (2009). Structure of European economies, view of Interindustrial backward linkages. Review of Economic Perspectives 9(4): 182-186.

KULIŠIĆ, B., LOIZOU, E., ROZAKIS, S., ŠEGON, V. (2007). Impacts of biodiesel production on Croa- tian economy. Energy Policy 35(12): 6036-6045. http://dx.doi.org/10.1016/j.enpol.2007.08.025

KURZ, H.D. (2011). Who is going to kiss sleeping beauty? On the "classical" analytical origins and perspectives of input-output analysis. Review of Political Economy 23(1): 25-47.

http://dx.doi.org/10.1080/09538259.2011.526292

LEONTIEF, W. (1966). Input-Output Economics. New York: Oxford University Press.

LEQUILLER, F., BLADES, D. (2006). Understanding National Accounts. Paris: OECD.

MEADE, D. S. (2001). The LIFT model. Inforum Working Papers, No. 01-002. Available at: <http://inforumweb.umd.edu/browse_inforum_wp.php>.

DE MESNARD, L. (1997). A biproportional filter to compare technical and allocation coefficient variations. Journal of Regional Science 37(4): 541-564. http://dx.doi.org/10.1111/0022-4146.00069

MORRISON, W.I., SMITH, P. (1974). Nonsurvey input-output techniques at the small area level: an evaluation. Journal of Regional Science 14(1): 1-13. http://dx.doi.org/10.1111/j.1467-9787.1974.tb00425.x

TEN RAA, T. (2007). The extraction of technical coefficients from input and output data. Economic Systems Research 19(4): 453-459.

http://dx.doi.org/10.1080/09535310701698597

SEVALDSON, P. (1970). The Stability of InputOutput Coefficients. Oslo: Central Bureau of Statistics. [Reprinted from: Applications of Input-Output Analysis, London: North-Holland Publishing Company, 1969.]

UNITED NATIONS (2009). System of National Accounts 2008. New York: United Nations Statistic Division.

UNITED NATIONS (1993). System of National Accounts 1993. New York: United Nations Statistic Division.

VAVRLA, L., ROJÍČEK, M. (2006). Sestavování symetrických input-output tabulek a jejich aplikace. Statistika 43(1): 28-43.

\section{Additional sources}

CZECH STATISTICAL OFFICE (2011). Supply and Use Tables. [Online database], accessed at 16. 12. 2011. Available at: <http://apl.czso.cz/pll/rocenka/>.

THE OFFICIAL WEB SITE OF THE NOBEL PRIZE (2011). The Sveriges Riksbank Prize in Economic Sciences in Memory of Alfred Nobel 1973. [Online], accessed at 2. 1. 2012. Available at: <http://www.nobelprize.org/nobel_prizes/economics/l aureat/1973/>. 
